\title{
Water sodium, urinary electrolytes, and blood pressure of adolescents
}

\author{
J.S ROBERTSON \\ From the District Medical Office, Department of Community Medicine, Scunthorpe Health Authority, \\ Scunthorpe DN15 8DT, UK
}

SUMMARY Blood pressure measurements were made on children in their fourth year at secondary schools in parts of Scunthorpe Health District supplied with drinking water of varying sodium content. Of the 3131 children, 2740 were examined (1394 boys and 1346 girls). Boys had slightly higher systolic pressures and slightly lower diastolic pressures than the girls. There was no difference between the blood pressure distributions of children in areas supplied with water containing $105 \mathrm{mg} / \mathrm{l}$ sodium, $50 \mathrm{mg} / 1$ sodium, or less than $15 \mathrm{mg} / 1$ sodium. Small differences were found in the weights of children in these areas, and slightly more of the children in the area supplied with water containing more than $105 \mathrm{mg} / \mathrm{l}$ sodium had relatives who had been treated for hypertension. Standardisation for these factors did not show any relation between water salinity and either systolic or diastolic blood pressure. Studies of the urinary sodium, potassium, and the ratios of these to creatinine on a sample of 769 boys showed no correlation with assessments of usual sodium intake, but urinary sodium correlated well with salt and fluid intake at the meal immediately preceding examination. The relation between median blood pressure and urinary sodium concentration and lack of a clear relation with sodium creatinine ratio supports the hypothesis that it may be the ratio of salt to fluid intake rather than total dietary sodium that is relevant to the regulation of blood pressure.

Attempts by a working group of the World Health Organisation in 1977 to set soundly based international standards for the sodium content of public water supplies were impeded by the dearth of reliable information as to the effects on the health of populations of potable water with differing concentrations of this element. ${ }^{1}$

In many parts of the world boreholes yield waters containing substantial amounts of sodium, and the rise in salinity of some surface water sources as a result of increasing use of salt to clear snow and ice from roads has caused concern. This has stimulated several studies aimed at ascertaining whether or not consumption of such waters constitutes a hazard to health.

Studies by Calabrese and Tuthill in the United States $^{23}$ and by Hofman et $a^{4}$ in the Netherlands have reported appreciably higher blood pressures in children living in areas supplied with water containing around $110 \mathrm{mg} \mathrm{Na} / 1$ than in children in areas of low water salinity. Although both were based on small numbers of subjects, and the pressures found were within the normal physiological range, these findings suggest the possibility that exposure of large populations to such water might be expected to result in a substantial increase in the incidence of hypertensive disease. These results, however, were surprising in view of the small contribution to the total sodium intake that such water would make to individuals consuming a normal western European or American diet. They conflict with evidence from a study of mortality in populations supplied with similar water which experienced fewer deaths from hypertension and from "all causes" than expected at national rates. ${ }^{5}$

The identification in Scunthorpe Health District of a substantially larger population of children exposed to public water supplies with an even wider range of sodium concentrations than those included in those surveys provided an opportunity to test the hypothesis that consumption of water of this quality influenced the blood pressures of children.

At the time when the survey was planned parts of the district were supplied with water from limestone sources partially softened by the soda lime process to yield a product containing around $130 \mathrm{mg} \mathrm{Na} / 1$. A 
larger area was supplied with water from boreholes in chalk and partially softened by base exchange to yield a water containing $80 \mathrm{mg} \mathrm{Na} / \mathrm{l}$. The rest of the district was supplied with unsoftened water from several boreholes and with sodium concentrations of between $5 \mathrm{mg} / \mathrm{l}$ and $15 \mathrm{mg} / \mathrm{l}$. The total population of the district is 193000 , and over 3000 children between the age of 14 and 14 years 11 months attended local schools and were available for study. Although by the time the necessary grant had been obtained the first stage of the phased reduction in degree of water softening had slightly reduced the salinity of the water, conditions still favoured the study, which began in January 1981. Figure 1 shows areas supplied with high, medium, and low sodium water. There are no interconnections between the low sodium supplies to the west of the river Trent and the sodium rich waters to the east, but within the borough of Scunthorpe some connecting pipes allow a limited amount of cross flow in the predominantly commercial central part of the town between the moderately saline supplies south of the railway lines and the sodium rich water supplies to the north. The sodium concentrations cited for the "sodium rich" supplies relate to water samples from the principal reservoir which receives a small proportion of its water from the less saline chalk sources. A proportion of the population which is supplied via water towers from the limestone source will have received a slightly more saline supply.

\section{Methods and materials}

Secondary schools in the parts of the district supplied with soda rich water from the limestone bores, schools in areas supplied with chalk waters of moderate salinity, and schools in areas receiving water of low salinity were identified. After obtaining consent from the education authority and the agreement of the headmasters, parents of children in their fourth year at these secondary schools were sent explanatory letters and asked to give consent to the examination of their children and provide information about any family history of hypertension.

Random zero sphygmomanometers were borrowed, and two state registered nurses were recruited and trained in their use. Their proficiency was checked by means of a special test tape. Recordings of the Korotkoff sounds from a series of blood pressure readings were played. The time interval between a marker signal and recognition of the appearance, modification, and disappearance of the sounds was measured by each nurse using a stop watch. After the nurses had shown their proficiency at this, appointments were made with the schools for

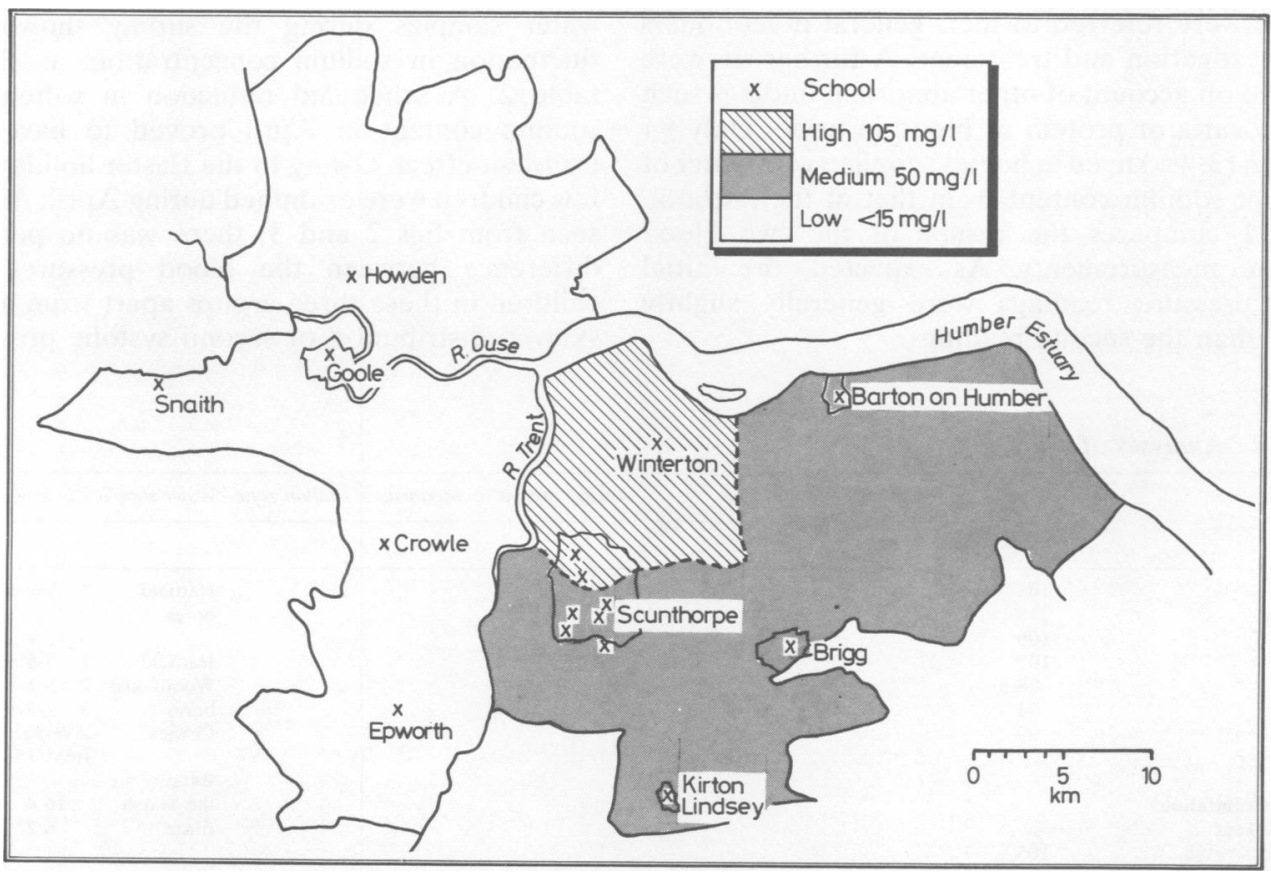

Fig 1 Scunthorpe Health District. Schools and water sodium zones. 
them to visit and examine those children whose parents had consented.

Each child was weighed and measured. An initial blood pressure measurement was taken. A questionnaire was then completed giving details of their dietary preferences and of the foods and beverages that had been consumed in the previous 24 hours. A second blood pressure measurement was then taken. Boys attending for examination in the mornings were asked to provide a specimen of urine for laboratory examination. All data collected were coded on to transfer sheets, from which they were entered into an ICL 1900 computer for analysis using the SPSS package.

\section{Results}

Headmasters of all but one of the 17 schools agreed to participate. Consent forms were sent to the parents of the $\mathbf{3 1 3 1}$ fourth year pupils registered at the $\mathbf{1 6}$ schools: 173 forms were not returned and 14 parents returned forms refusing consent.

Of the 2944 to be tested, 144 children were absent from school on the days of the test and 49 had to be omitted when illness of a nurse necessitated cancellation of a visit at the end of the project. A further 11 children were omitted because the child refused to be examined or unsuccessful attempts at examination. Altogether 2740 children were examined. Thirteen whose blood pressures exceeded $160 / 90$ were referred to their general practitioners for investigation and treatment. A further six were referred on account of other abnormal findings such as glycosuria or protein or blood in urine. Only 94 children (3.4\%) lived in homes supplied with water of different sodium content from that at their school. Table 1 compares the results of the two blood pressure measurements. As expected, the initial blood pressure readings were generally slightly higher than the second readings.
Table 1 Blood pressure measurements

\begin{tabular}{lcc}
\hline & Boys & Girls \\
\hline No & 1394 & 1346 \\
Mean 1st systolic & 117.5 & 115.5 \\
Mean 2nd systolic & 111.1 & 109 \\
Correlation coefficient & 0.797 & 0.796 \\
Mean 1st diastolic & 63.2 & 65.2 \\
Mean 2nd diastolic & 61.2 & 63 \\
Correlation coefficient & 0.707 & 0.726 \\
\hline
\end{tabular}

No differences were found between the blood pressures of children in areas where the sodium content of the water was high, medium, or low.

The differences between first and second blood pressure measurements are believed to be predominantly due to the effects of anxiety and mediated by catecholamines. Consequently, the second reading is the better indicator of an individual's normal resting blood pressure. Figures 2 and 3 show the blood pressure distributions, based on second readings, of boys and girls in the high, medium and low sodium zones.

By the time the survey started, the first stage of a four step reduction in degree of water softening and hence in salinity of the water had been implemented. Consequently, the areas with highest salinity were receiving water normally containing $105 \mathrm{mg} \mathrm{Na} / \mathrm{l}$ and the intermediate areas $50 \mathrm{mg} \mathrm{Na} / \mathrm{l}$. Analyses of water samples during the survey showed some fluctuation in sodium concentration, as shown in table 2. A scheduled reduction in softening and sodium content in April proved to have only a transient effect. Owing to the Easter holidays only a few children were examined during April. As may be seen from figs 2 and 3 , there was no perceptible difference between the blood pressures of the children in these three groups apart from a slightly skewed distribution of second systolic pressures in

Table 2 Analyses of water samples

\begin{tabular}{|c|c|c|c|c|}
\hline & \multirow{2}{*}{$\begin{array}{l}\text { Water supplied in high sodium zone } \\
\text { (mg/l Na) }\end{array}$} & \multirow[t]{2}{*}{ Water supplied in intermediate sodium zone } & \multicolumn{2}{|c|}{ Water supplied in low sodium zone } \\
\hline & & & & \\
\hline January & 108 & - & Hatfield & $19.9 \pm 0.5$ \\
\hline February & 118 & 51 & bores & $210.6 \pm 0.8$ \\
\hline March & 106 & 50 & & $312.1 \pm 0.5$ \\
\hline April & 107 & 27 & Hatfield & $17.5 \pm 0.6$ \\
\hline Mav & $88 \cdot 5$ & 47 & Woodhouse & $28.1 \pm 0.5$ \\
\hline June & 94 & 47 & bores & $39.8 \pm 0.6$ \\
\hline July & 99 & 59 & Cowick & $\begin{array}{l}\text { Average } 12 \\
(\max 15, \min 11)\end{array}$ \\
\hline $\begin{array}{l}\text { Mean concentration } \\
\text { when relevant }\end{array}$ & & & $\begin{array}{l}\text { Barmby on } \\
\text { the Marsh } \\
\text { Elton }\end{array}$ & $\begin{array}{r}16 \cdot 4 \\
6 \cdot 2\end{array}$ \\
\hline schools examined & 105 & 47 & & \\
\hline
\end{tabular}

Information for the low sodium zone is given by individual bore, not by month, owing to the small variation in sodium concentration over time for these supplies. 


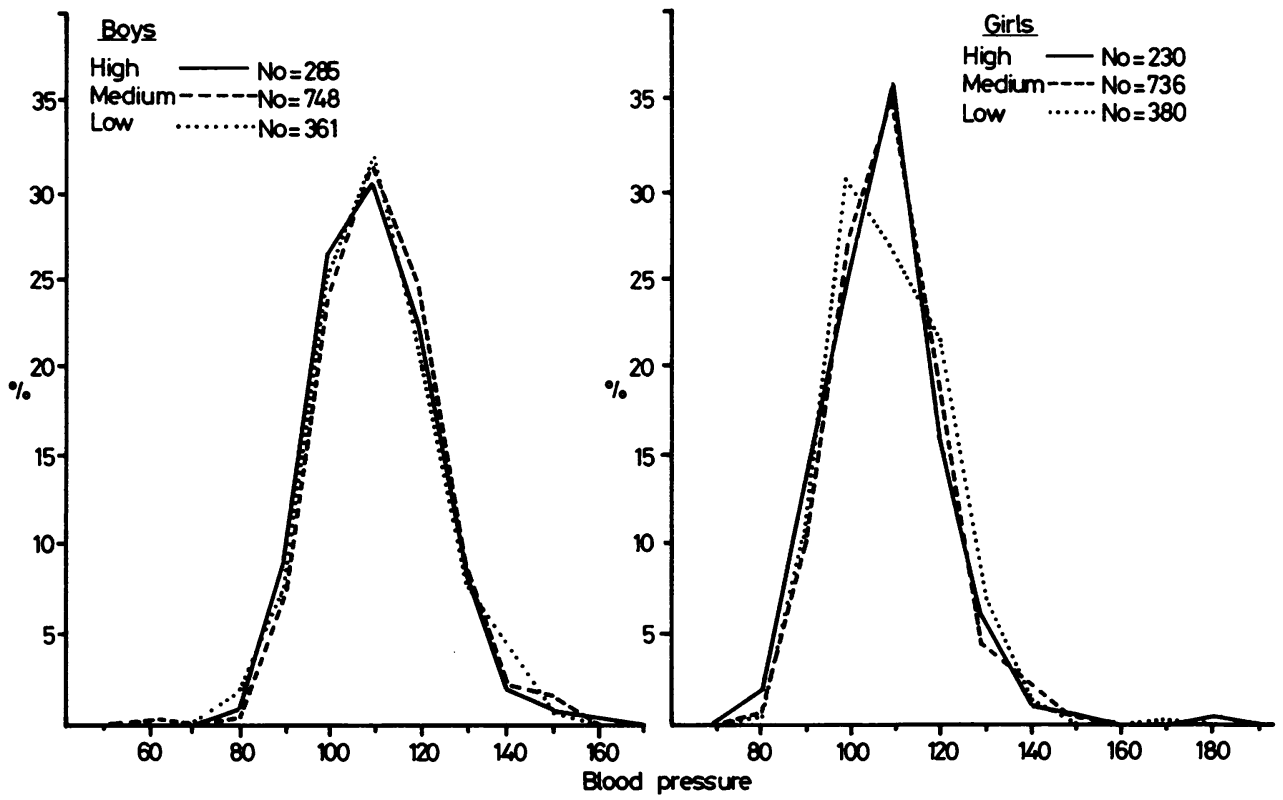

Fig 2 Second systolic blood pressure readings of pupils in water sodium zones.
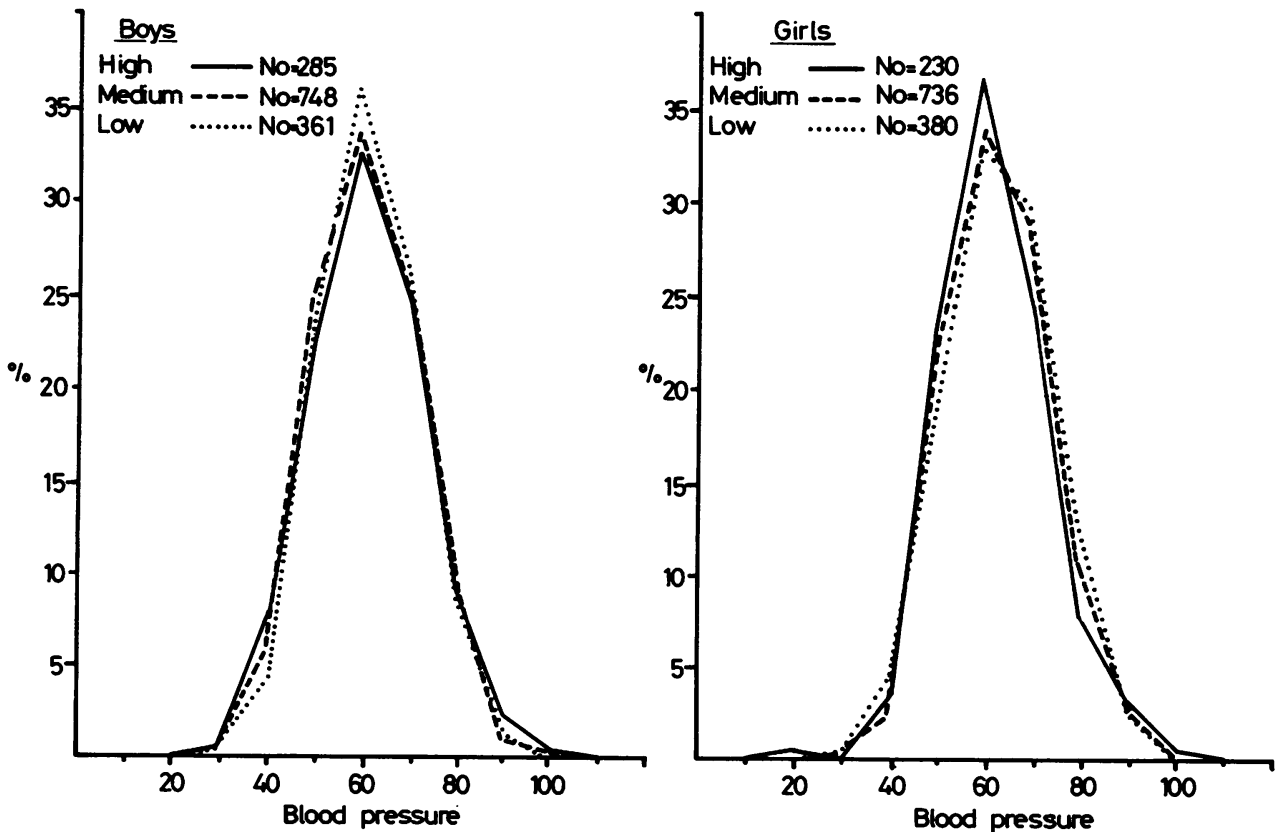

Fig 3 Second diastolic blood pressure readings of pupils in water sodium zones. 
the $\mathbf{3 8 0}$ girls in the low sodium areas. Despite the large numbers concerned, none of the differences between blood pressures of children in the different areas approached statistical significance.

\section{EFFECT OF WEIGHT}

The mean weights of pupils varied between the schools in high, medium, and low salinity areas. The mean weight of children at the schools in the high sodium areas was $54.8 \mathrm{~kg}$, in the schools with $50 \mathrm{mg} / 1$ it was $55.5 \mathrm{~kg}$, and in the low $\mathrm{Na}$ schools $56.6 \mathrm{~kg}$. This is almost certainly because the schools in the high and medium sodium areas had to be examined early in the programme before a scheduled modification in treatment reduced the salinity of their water. Since adolescence is a time of rapid growth this slight delay in testing the low sodium zone schools is reflected in a slightly greater mean body weight.

Table 3 shows the relation betwen body weight and blood pressure.

\section{EFFECT OF FAMILY HISTORY}

Blood pressures of children with no family history were compared with those of children whose mothers had been treated for hypertension, with those who had another close relative affected, and with children who had two or three or more relatives who had been treated for hypertension.

Table 4 shows mean blood pressures of children with differing family histories of hypertension.

From these it is apparent that although the mean systolic and mean diastolic pressures of children with no family history were slightly lower than those with

Table 3 Blood pressure by weight

\begin{tabular}{|c|c|c|c|c|c|}
\hline Weight (kg) & No & Mean systolic & Standard deviation & Mean diastolic & Standard deviation \\
\hline \multicolumn{6}{|c|}{ Boys } \\
\hline$<42 \cdot 5$ & 92 & 101.9 & 10.9 & $56 \cdot 3$ & $11 \cdot 5$ \\
\hline $42 \cdot 5-47 \cdot 4$ & 157 & $106 \cdot 5$ & $11 \cdot 7$ & $58 \cdot 8$ & $10 \cdot 7$ \\
\hline $47 \cdot 5-52 \cdot 4$ & 253 & $108 \cdot 1$ & $10 \cdot 2$ & 59.8 & $10 \cdot 5$ \\
\hline $52 \cdot 5-57 \cdot 4$ & 278 & $111 \cdot 8$ & $12 \cdot 0$ & 60.7 & $10 \cdot 5$ \\
\hline $57 \cdot 5-62 \cdot 4$ & 267 & $111 \cdot 9$ & $11 \cdot 3$ & $61 \cdot 9$ & $10 \cdot 3$ \\
\hline $62 \cdot 5-67 \cdot 4$ & 167 & $114 \cdot 6$ & $11 \cdot 8$ & $63 \cdot 8$ & $10 \cdot 9$ \\
\hline$\geqslant 67.5$ & 180 & $118 \cdot 2$ & $14 \cdot 2$ & $65 \cdot 3$ & $10 \cdot 5$ \\
\hline Total & 1394 & & & & \\
\hline \multicolumn{6}{|c|}{ Girls } \\
\hline$<42 \cdot 5$ & 60 & $105 \cdot 1$ & $11 \cdot 5$ & $58 \cdot 3$ & $12 \cdot 0$ \\
\hline $42 \cdot 5-47 \cdot 4$ & 167 & $104 \cdot 8$ & $10 \cdot 1$ & $60 \cdot 1$ & 9.9 \\
\hline $47 \cdot 5-52 \cdot 4$ & 350 & 107.6 & 10.6 & $63 \cdot 1$ & $10 \cdot 7$ \\
\hline $52 \cdot 5-57 \cdot 4$ & 342 & $107 \cdot 9$ & 10.4 & 62.4 & $10 \cdot 3$ \\
\hline $57 \cdot 5-62 \cdot 4$ & 214 & 109.9 & $11 \cdot 4$ & $63 \cdot 8$ & $10 \cdot 0$ \\
\hline $62 \cdot 5-67 \cdot 4$ & 117 & $113 \cdot 7$ & $12 \cdot 3$ & $64 \cdot 4$ & 9.6 \\
\hline$\geqslant 67.5$ & 96 & $120 \cdot 3$ & $13 \cdot 2$ & $69 \cdot 1$ & $11 \cdot 7$ \\
\hline Total & 1346 & & & & \\
\hline
\end{tabular}

Table 4 Second blood pressure readings by family history

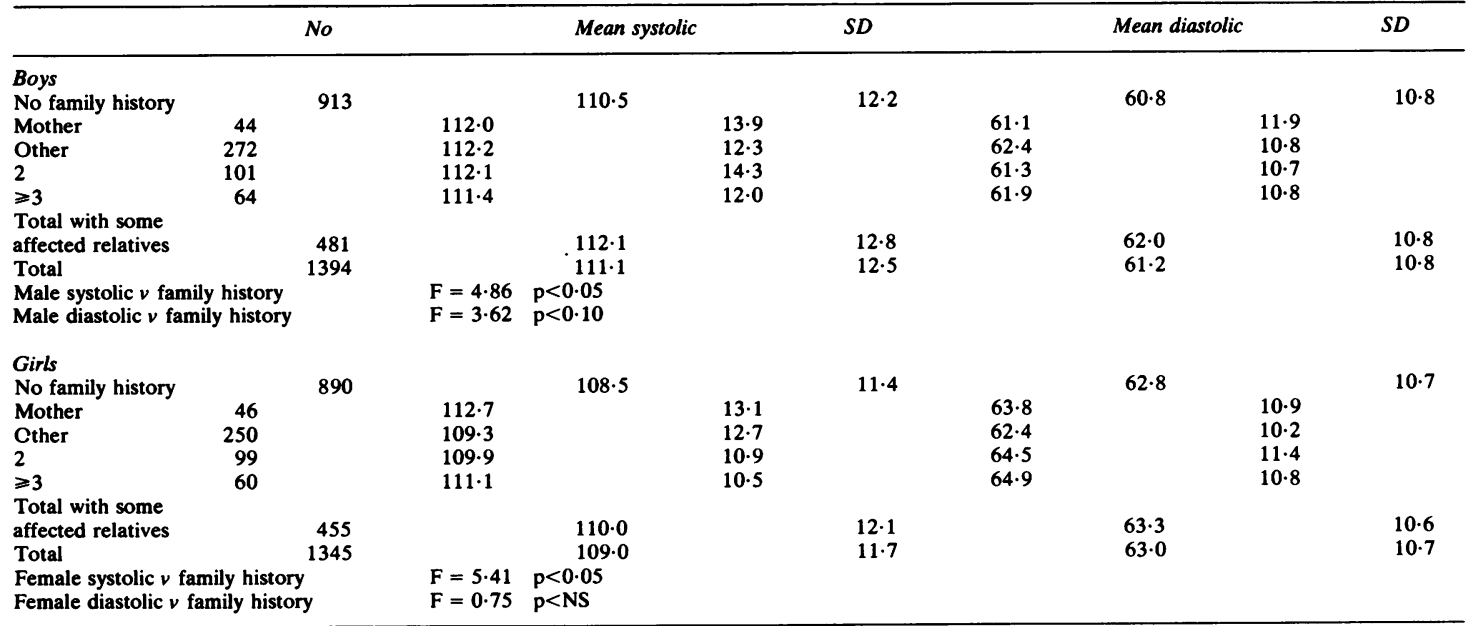


family histories, strength of the family history had no effect.

When the frequencies with which a family history was reported in respect of children attending the schools in areas of high, medium, and low water salinity were compared, an excess of such histories was found in the high sodium area (table 5).

To eliminate any bias due to differences in weight and family history the blood pressures were standardised for these.

Table 5 Frequency of family history: both sexes

\begin{tabular}{lrrr}
\hline Salinity & High & Medium & Low \\
\hline \% With no & & & \\
family history & 60.0 & 67.6 & 66.3 \\
Mother & 4.0 & 3.5 & 2.2 \\
Other & 20.2 & 17.6 & 21.6 \\
2 & 9.9 & 6.7 & 6.8 \\
$\geqslant 3$ & 5.9 & 4.8 & 3.1 \\
\hline
\end{tabular}

\section{EFFECT OF TIME OF EXAMINATION}

Comparison between the blood pressure of children tested in the mornings and those tested in the afternoons confirmed the existence of a diurnal variation. In both sexes mean systolic pressures were lower in the morning and diastolic pressure lower in the afternoons. Nevertheless, as the proportions of children examined in the mornings and in the afternoons did not differ between the groups in high, medium, and low water sodium areas it was not necessary to standardise for this factor.

EFFECT OF WATER SALINITY ON " SALT APPETITE,",

Many of the population studies of the relation between sodium ingestion and blood pressure have been based on relatively crude methods of assessing daily salt intake from the diet, such as whether the subjects add salt at table. Studies on individuals whose salt intake has been accurately measured have shown little or no effect from quantities greater than that present in two litres of water with $105 \mathrm{mg}$ $(4.5 \mathrm{mMol}) \mathrm{Na} / \mathrm{l}$. Clearly no effect would be expected from moderate amounts of salt in the water if this was compensated by a corresponding reduction in salt added to food. In view of the small relative contribution made by sodium from water to the total ingested, an effect as great as that found by Calabrese and Tuthill ${ }^{2}$ would only be expected if salinity of water actually enhanced the salt appetite, causing people to consume more salt with their foods. In an attempt to test whether this was so children taking part in this survey were asked a series of questions about their dietary preferences and also about the foods and drinks consumed during the previous 24 hours.

On the basis of their answers the children were allotted "salt preference scores" and "sugar preference scores" in respect of preference for snacks, preference for main meals, and foods eaten in the past day. Their preferences for "snacks" were assessed as follows.

Each child was asked about personal consumption of snacks - for instance, potato crisps, salted peanuts, cheese straws, other savoury snacks, soups, chips/fish and chips, peanut butter, toffees, chocolate, other sweets, marmalade/jam, puddings, and canned/bottled drinks.

Marks were awarded in respect of those snacks that contain salt on the basis of frequency of consumption: rarely $=0$; occasionally $=1$; and often $=2(0$ to 14$)$. The totals of these were taken as a measure of salt from these sources. "Sugar" scores were assessed in a similar manner.

The mean salt scores of children from the high, medium, and low salinity zones did not differ (table 6).

Table 6 Salty snack preference score by salinity zone

\begin{tabular}{|c|c|c|c|}
\hline & Mean salt scores for snacks & Standard deviation & No \\
\hline High & $5 \cdot 15$ & $2 \cdot 1$ & 507 \\
\hline Mediưm & 5.08 & $2 \cdot 1$ & 1482 \\
\hline Low & $5 \cdot 17$ & $2 \cdot 1$ & 735 \\
\hline Total & $5 \cdot 12$ & $2 \cdot 1$ & 2724 \\
\hline
\end{tabular}

Salt intake from main meals was assessed in a similar manner. Children were asked whether they added salt at table to a range of foods. Marks were awarded in a similar manner as above: rarely $=0$, occasionally $=5$, and often $=10(0$ to 20$)$. On this basis too the differences in mean scores in children from the three zones showed no relationship to the salinity of the water (table 7).

\section{RESULTS OF URINE ANALYSES}

Urine samples were collected from the 769 boys who were examined in the mornings. No correlation was found between either urinary sodium concentration

Table 7 Main meal salt score by salinity zone

\begin{tabular}{lllr}
\hline & $\begin{array}{l}\text { Mean salt scores for main } \\
\text { meals }\end{array}$ & Standard deviation & No \\
\hline High & 8.07 & 6.6 & 507 \\
Medium & 7.74 & 6.1 & 1482 \\
Low & 8.48 & 6.7 & 735 \\
Total & 8.00 & 6.3 & 2724 \\
\hline
\end{tabular}


or sodium/creatinine ratio and the snack or main meal salt scores. As might be expected, however, significant relations were found between urinary sodium concentrations and the breakfast salt/fluid ratio, and between the sodium/creatinine ratio and the breakfast salt score. This reflects the action of the body's homeostatic mechanisms and confirms the view that the salt and water regulating mechanisms respond quickly to variations in intake. It also indicates that individuals vary their fluid and salt consumption widely from meal to meal and from day to day, and that there is not sufficient consistency in their intake to validate salt preference scores as indices of total salt consumption.

Although the variation in both systolic and diastolic blood pressure within each group was great and the differences between groups with different urine quality did not reach statistical significance, the median diastolic and systolic pressures were found to be directly proportional to urinary sodium concentrations (figs $4 a$ and $b$ ). No clear trend was found between median systolic or diastolic pressure and sodium creatinine ratio.

A significant direct relation was found between second systolic blood pressures and the sodium/potassium ratio of the urine $(F=3.882$ $p=0.05)$. The relation between diastolic pressure and sodium/potassium ratio in urine was not statistically significant.

\section{Discussion}

Whether dietary salt contributes to the aetiology of essential hypertension is still uncertain. Comparisons between different populations have shown that some populations whose diets contain litle salt have a low prevalence of hypertension and their blood pressures do not rise with age, whereas other populations whose diets are rich in salt show a high prevalence of hypertension. ${ }^{6}$ The populations with low salt diets and little hypertension, however, live in primitive conditions and their way of life differs profoundly from that of the Japanese, American, and western European populations with whom they have been compared. No relation has been found between the salt consumption and blood pressures of individuals within the same cultural groups when these have been compared. ${ }^{78}$

Normotensive and hypertensive subjects differ in their response to salt restriction. The fall in blood pressure achieved by the use of Kempners fruit and rice diet for the treatment of severe hypertension was shown to be due to restricted sodium intake. More moderate salt restriction has been reported to be as

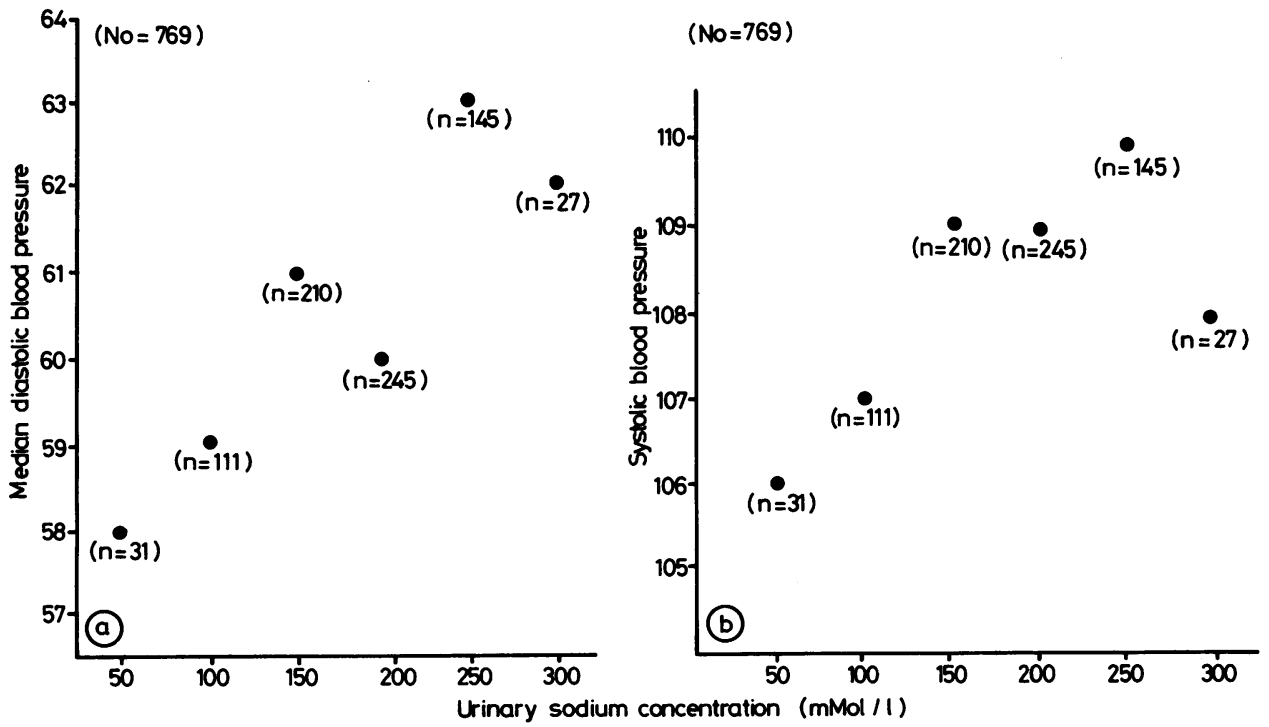

Fig 4 (a) Median diastolic blood pressure and (b) Medium systolic blood pressure, both by urinary sodium concentration. (Numbers in each group are shown in parentheses.) 
effective as conventional treatment with diuretics or beta blockers in controlling the pressure of subjects with moderate hypertension. ${ }^{9}$ In other studies the blood pressures of normotensive subjects and of patients with mild hypertension have not varied with changes in dietary sodium. ${ }^{10}$

By selective breeding, Dahl et al produced two strains of rat, one of which became hypertensive when given a sodium rich diet and one strain which did not. ${ }^{11}$ Kawasaki et al have suggested that like Dahl's rats, hypertensive patients may be divided into salt sensitive and salt resistant groups. ${ }^{12}$ It has recently been suggested that the "sodium pump"mechanism which maintains the differential between the low sodium concentration within cells and the high concentration in extracellular fluids may be defective in sufferers from essential hypertension. ${ }^{13}{ }^{14}$ This mechanism may also be concerned in the reclamation of sodium by the cells of the renal tubules from the glomerular filtrate of salt deficient subjects. Such a defect could gravely impair ability to conserve salt, rendering affected subjects vulnerable to salt depleting diarrhoeal diseases. Consequently, the absence of hypertensive subjects from populations whose ancestors have lived for millennia on diets low in salt and in primitive conditions where enteritis is prevalent could be due to evolutionary pressures. Such populations also suffer high infant mortality from diarrhoeal diseases. Consequently, few individuals with defective power to conserve sodium would survive to adult life.

The favourable mortality experience of East Anglian and Lincolnshire communities supplied with saline water during the $1950 \mathrm{~s}$ and $1960 \mathrm{~s}^{5}$ as compared with the rest of England and Wales lends support to this hypothesis. Although morbidity data were not available, there was a deficit in deaths attributed to hypertension in these communities.

The observations of Calabrese and Tuthill ${ }^{2}$ and of Hofman et al, ${ }^{4}$ however, appeared to indicate that although none were hypertensive, the blood pressures of young people in areas where the drinking water contained $5 \mathrm{mMol} / \mathrm{l}$ were slightly raised. If such a general increase applied to the entire population it should result in a substantial increase in the prevalence of pressures in excess of $160 / 90$ in the older age groups. The results of this survey do not support their contention. Even after standardisation for weight and family history there was no perceptible difference between the blood pressures of children in the zones supplied with water of high, intermediate, or low salinity.

These differences require explanation. In all these studies precautions were taken to avoid observer bias. The principal differences between this and the other studies were that in this survey the numbers examined were substantially larger, the number of schools where examinations were conducted was greater, and the first readings were disregarded so that the short term catecholamine mediated rise in pressure due to apprehension would not bias the results. It is conceivable that in the other studies where only a few schools were included and initial blood pressure readings were included in the analysis, inclusion of a school where the examinations were conducted in a less restful or more "threatening" environment could have led to bias.

Most Europeans and North Americans consume $5-15 / \mathrm{g} /$ day of salt $(86-258 \mathrm{mMols})$. Thus the 10 mMols contributed by an average day's intake of water from the sodium rich supplies of the areas studied would represent only a small contribution. The hypothesis that subjects drinking saline water might add more salt to their food was not supported by the results of this inquiry.

\section{Conclusions}

The results of this survey indicate that consumption of water containing up to $5 \mathrm{mMol}$ salt/l does not cause any rise in blood pressures of adolescents. It is suggested that total sodium intake is of less relevance to health than the ratio of salts to fluids ingested.

I am indebted to the Medical Research Council for funding this study; the education committee of the Humberside County Council for permission to undertake it; the head teachers of secondary schools in the county for their help in carrying it out; $\mathbf{M r}$ Frank Wharton, Operational Research Department, Hull University, for computer analyses of the data; Dr Kennedy, pathologist at Scunthorpe District General Hospital for undertaking assays of urine; and Mrs Sumner at the Anglian Water Authority for weekly analyses of water for sodium.

\section{References}

${ }^{1}$ World Health Organisation Working Group. Sodium chlorides and conductivity in drinking water. (Euro reports and studies No 2.) The Hague: WHO 1978.

${ }^{2}$ Calabrese EJ, Tuthill RW. Elevated blood pressures and high sodium levels in the public drinking water. Arch Environ Health 1977; 32: 200-2.

${ }^{3}$ Tuthill RW, Calabrese EJ. Drinking water sodium and blood pressure in children-a second look. Am J Public Health 1981; 71: 722-9. 
${ }^{4}$ Hofman A, Valkenburg HA, Vaandrager GJ. Increased blood pressure in schoolchildren related to high sodium levels in drinking water.J Epidemiol Community Health 1980; 34: 179-81.

${ }^{5}$ Robertson JS, Slattery JA, Parker V. Water sodium, hypertension and mortality. Community Medicine 1979; 1: 295-300.

${ }^{6}$ Dahl LK. Possible role of chronic excess salt consumption in the pathogenesis of essential hypertension. Am J Cardiol 1961; 8: 571-5.

${ }^{7}$ Stuessen J, Faggard R, Lynen P, Amery A, Bulpitt C, Joossens JV. Salt and blood pressure in Belgium. $J$ Epidemiol Community Medicine 1981; 35: 256-61.

${ }^{8}$ Beevers DG, Hawthorn VM, Padfield PL. Salt and blood pressure in Scotland. Br Med J 1980; 281: 641-2.

${ }^{9}$ Morgan T, Adam W, Gillies A, Wilson M, Morgan G, Carney $S$. Hypertension treated by salt restriction. Lancet 19788; i; 227-30.
${ }^{10}$ Watt GCM, Edwards C, Hart TJ, Hart M, Walton P, Foy CJW. Dietary sodium restriction for mild hypertension in general practice. $\mathrm{Br}$ Med J 1983; 286: 432-6.

${ }^{11}$ Dahl LK, Heine M, Tassinari L. Effects of chronic excess salt ingestion. Evidence that genetic factors play an important role in susceptibility to experimental hypertension. J Exp Med 1962; 115: 1173-90.

${ }^{12}$ Kawasaki T, Delea CS, Bartter FC, and Smith $H$. The effect of high sodium and low sodium intakes on blood pressure and other related variables in human subjects with idiopathic hypertension. Am J Med 1978; 64: 193-8.

${ }^{13}$ Anonymous. Essential hypertension-another defect?. Lancet 1980; i: 1227-9.

${ }^{14}$ Garay RP, Elghozi JL, Dagher G, Meyer P. Laboratory distinction between essential and secondary hypertension by measuremer.t of erythrocyte cation fluxes. $N$ Eng J Med 1980; 302: 769-71. 